\title{
Methylene blue as an antioxidant agent in experimentally- induced injury in rat liver
}

\author{
Bozkurt $\mathrm{B}^{1}$, Dumlu EG ${ }^{1}$, Tokac $\mathrm{M}^{1}$, Ozkardes $\mathrm{AB}^{2}$, Ergin $\mathrm{M}^{3}$, Orhun $\mathrm{S}^{4}$, Kilic $\mathrm{M}^{2}$ \\ Ataturk Training and Research Hospital Department of General Surgery, Ankara, Turkey. \\ birkan.bozkurt@gmail.com
}

\begin{abstract}
Background: We aimed to test the methylene blue (MB) as a dye and also to test its antioxidant activities in devascularization-induced liver injury.

Methods: Twenty rats weighing 240-280 g were randomly divided into two groups, each containing 10 rats. High-grade liver injury was induced by using a pair of long pliers with blades. MB was injected into portal vein of the rats with no hepatic injury (Group 1; control group) and those with injured livers (Group 2; injury group). Liver and hepatic function tests, paraoxonase, stimulated paraoxonase, arylesterase activity, total antioxidant, and oxidant status were evaluated before and $24 \mathrm{~h}$ after MB injection.

Results: MB did not stain the non-perfused area. Total antioxidant status decreased significantly in Group 2 at hour 24 compared to Group 1. In Group 2, total antioxidant status was lower at hour 24 compared to hour 0 . Total oxidant status in Group 2 at hour 0 increased significantly compared to Group 1. Total oxidant status in Group 2 at hour 24 was lower compared to that at hour 0 . Lipid peroxidation parameters did not alter due to devascularization. Conclusion: MB is useful in defining the devascularization area. Moreover, it showed to have a beneficial effect on oxidant status (Tab. 3, Fig. 3, Ref. 25). Text in PDF www.elis.sk.

Key words: devascularization, liver, injury, methylene blue, rat.
\end{abstract}

\section{Introduction}

The liver is the most commonly injured organ during abdominal trauma. Grade IV to V of liver injury leads to mortality in range of $35-80 \%(1,2)$. Treatment approach includes surgical or non-surgical interventions. Non-surgical intervention is becoming popular for high-grade liver injuries since surgery is associated with high mortality rates (3).

The major determining factor for treatment of liver injury is the hemodynamic status of the patient. Non-operative treatment is indicated in patients with stable hemodynamic status and isolated organ injury $(4,5)$. In instable patients with uncontrolled bleeding, the requirement of surgery remains to be a controversial issue. Surgical techniques include packing, anatomic liver resection, selective vessel ligation, resectional debridement, parenchymal sutures, and hepatectomy with liver transplantation $(6,7)$.

Devascularization injury is a life-threatening form of liver injury resulting from disrupted vascular inflow to one or more hepatic segments (5). It is important to be able to diagnose this type of injury, since stable patients may develop decompensation due to septic complications. It has been suggested that surgical resec-

'Ataturk Trainig and Research Hospital Department of General Surgery, Ankara, Turkey, ${ }^{2}$ Yildirim Beyazit Trainig and Research Hospital Department of General Surgery, Ankara, Turkey, ${ }^{3}$ Ataturk Trainig and Research Hospital Department of Biochemistry, Ankara, Turkey, and ${ }^{4}$ Ataturk Trainig and Research Hospital Department of Pathology, Ankara, Turkey

Address for correspondence: B. Bozkurt, Dr, Atatürk Training and Research Hospital, Department of General Surgery, Bilkent, Ankara, Turkey Phone: +90.312.2912525/4510, Fax: +90.312.2912718 tion is necessary in patients with extensive liver necrosis before the development of secondary complications (2).

Hepatic injury score is determined by parenchymal disruption as seen on admission computed tomography (CT). However, the grade of injury alone does not determine the need for surgical intervention since parenchymal disruption may be due to hemorrhage or devascularization injury $(8,2)$. If the patient is stable and has hemorrhage, non-surgical treatment is likely to be successful (9). Conversely, if the parenchymal disruption is secondary to devascularization, non-surgical management is run at risk of septic complications. Moreover, there is no method to detect the nonperfused area precisely during intraoperative procedure to help with the decision-making. Therefore, it is crucially important to indentify the devascularized area precisely. (2).

Methylene blue (MB) is a liposoluble dye marking the tissue, and thus its injection allows to localize a tissue such as tumor or lymph nodes $(10,11)$. In addition, MB has been shown effective against oxidative stress $(12,13)$. It is also known that hepatic devascularization increases oxidative stress and lipid peroxidation parameters $(14,15)$.

In the present study, MB was tested for identification of nonperfused tissue in rat liver with experimentally induced devascularization injury. Additionally, antioxidant properties of MB were also examined for oxidative stress and lipid peroxidation parameters in serum.

\section{Materials and methods}

\section{Study design}

The present study is a prospective, randomized, and controlled 


\section{7-161}

experimental study. It was approved by Ankara Hospital Ethics Committee for Animal Experiments. All animal experiments were carried out in accordance with the rules issued by European Community Council.

\section{Animals and experimental procedure}

Female Wistar albino rats weighing 240-280 g were used in this study. They were maintained under standard conditions of room temperature and humidity. The rats were fed with standard rat chow and fasted with free access to water for 12 hours before the experiment

The rats were randomly divided into two groups, each containing 10 rats as follows:

Group 1 (control group); MB was injected into portal vein of the rats with no hepatic injury.

Group 2 (injury group); MB was injected into the portal vein of the rats with injured liver.

\section{Surgical procedure}

The rats were anesthetized with intramuscular ketamine hydrochloride (75 mg/kg, Ketalar, Parke Davis, Eczacibasi, Istanbul, Turkey) and intraperitoneal xylazine ( $5 \mathrm{mg} / \mathrm{kg}$, Alfazyne $2 \%$, Ege Vet, Izmir, Turkey). The abdomen was opened through an upper mid-line incision $3 \mathrm{~cm}$ in length and the liver was exposed. High grade liver injury was induced by using a pair of long pliers with blades $1.5 \mathrm{~cm}$ in length. "Liver Injury Scale of the American Association for the Surgery of Trauma" was accepted as the guide for inducing the injury (16). The portal vein was exposed following injury, and a disposable $22 \mathrm{G}$ catheter was inserted $1-2 \mathrm{~cm}$ into the proximal vein toward the liver. Injection of $\mathrm{MB}$ was performed through the catheter $(1.5 \mathrm{mg} / \mathrm{kg}-0.2 \mathrm{~mL}$ in $2 \mathrm{ml}$ of saline, $2 \%$ MB, Lexi-Comp. Inc., Hudson, Ohio, USA). Following MB injection, stained and unstained areas were observed and recorded. Discoloration times were also recorded. Additionally, the times of staining and discoloration onsets were noted. Catheters were removed after discoloration. Liver samples of $1-3 \mathrm{~cm}^{3}$ were taken from the unstained areas and fixed with $4 \%$ buffered formaldehyde for histopathological evaluation. Liver injury was repaired by simple sutures in the presence of uncontrollable bleeding from borders. The surgical procedure consisting of repairing the liver injury and abdominal closure was completed within $10 \mathrm{~min}$ (16).

\section{Laboratory and pathological evaluation}

Blood samples were taken from tail veins of rats before (at hour 0 ) and 24 hours after MB injection to evaluate the serum levels of albumin, alanine transferase (ALT), aspartate aminotransferase (AST), bilirubin, creatinine, urea, paraoxonase (PON), stimulated paraoxanase (SPON), and arylesterase. Hematocrit and total oxidant status were also examined.

\section{Measurement of total antioxidant status}

A fully automated calorimetric measurement method was used to assess the total antioxidant status (17). In this method, e2+-odianisidine complex reacts with hydrogen peroxide in Fenton type reaction, producing hydroxyl radical. This strong reactive oxygen type reacts with colorless o-dianisidine molecule. As a result, bright yellowish-brown dianisyl radicals are produced, and participate in further oxidation reactions increasing the color production. This reaction is inhibited and the coloration is stopped by antioxidants in test tube to a degree that is proportional to their concentrations. The assay is performed by the measurement with automatic spectrophotometric analyzer and the results are expressed as millimolar Trolox equivalent per liter (mmol Trolox eq/L).

\section{Measurement of total oxidant status}

The total oxidant status was determined using a fully automated colorimetric measurement (18). Ferrous ion-o-dianisidine complex is oxidised to ferric ion by oxidants in the sample. The glycerol speeds up this reaction approximately three times. A colorful complex with "xylenol orange" is produced by the ferric ions in acidic media. The color intensity is measured spectrophotometrically and is proportional to the amount of oxidants. Results were expressed as micromolar hydrogen peroxide equivalent per liter $\left(\mu \mathrm{mol} \mathrm{H}_{2} \mathrm{O}_{2}\right.$ eq/L).

\section{Measurement of PON, SPON, and arylesterase activities}

Commercial Rel assay kits were used for the measurement of PON and arylesterase activity (19). PON activity was measured in absence and presence of $\mathrm{NaCl}$ (SPON). PON1 activity was determined with the increase in absorbance at $412 \mathrm{~nm}$ resulting from the formation of 4-nitrophenol in the presence of PON as substrate. The absorptivity coefficient of $18290 \mathrm{M}^{-1}$ was used for calculation of enzymatic activity. Phenylacetate was used as substrate for determination of arylesterase activity. Enzymatic activity was calculated by using molar absorptivity coefficient of 1301 $\mathrm{M}^{-1} \mathrm{~cm}^{-1}$ of phenol. The enzymatic activity was expressed as U/L.

\section{Statistical analysis}

All data in the text and tables are presented as mean \pm standard deviation. Within group comparisons were performed using the paired sample $t$ test. The student $t$ test was used to compare variables between groups. Statistical analyses were performed using SPSS 11 software. The level of statistical significance was set at $\mathrm{p}<0.05$.

\section{Results}

\section{Staining and discoloration times}

In Group 1 (control group), liver parenchyma was stained homogeneously. Non-perfused areas of the liver in Group 2 (injury group) were not stained. As shown in Table 1, the mean onset time of staining in perfused parenchyma was $3.89 \pm 0.18 \mathrm{sec}$ in controls and $3.31 \pm 0.27 \mathrm{sec}$ in cases $(\mathrm{p}>0.05)$. The mean dis-

Tab. 1. Staining and discoloration times between groups.

\begin{tabular}{lccc}
\hline & $\begin{array}{c}\text { Group 1 } \\
(\text { Control, } \mathrm{n}=10)\end{array}$ & $\begin{array}{c}\text { Group 2 } \\
\text { (Liver injury, n=10) }\end{array}$ & $\mathrm{p}$ \\
\hline Staining onset time (sec) & $3.89 \pm 0.18$ & $3.31 \pm 0.27$ & $<0.001$ \\
Discoloration time (sec) & $22.11 \pm 1.02$ & $19.92 \pm 0.99$ & $<0.001$ \\
\hline
\end{tabular}

Data are given as mean \pm standard deviation. 


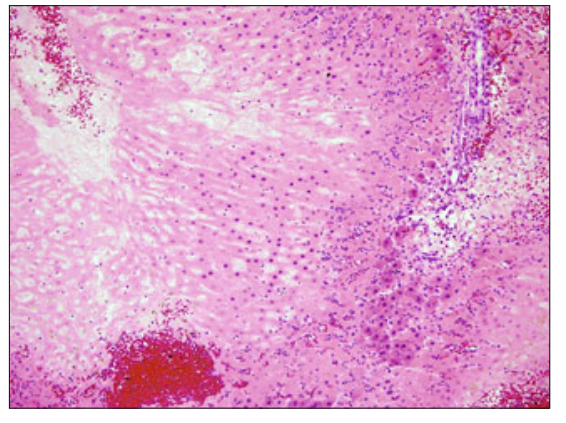

Fig. 1. Hepatocytes undergoing necrosis and polymorphonuclear leukocytes are seen. (HE x200)

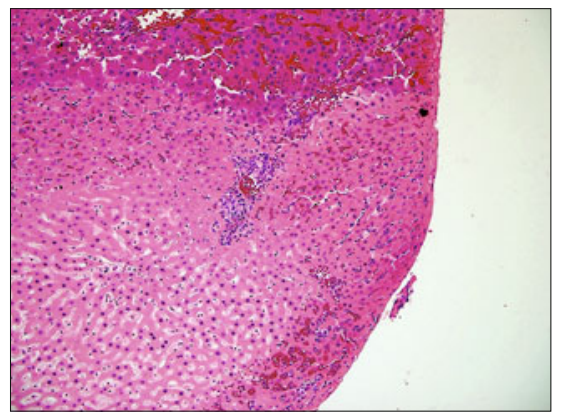

Fig. 2. Subcapsular bleeding, necrosis and po- Fig. 3. Geographic necrosis is seen in liver.

lymorphonuclear leukocytes are seen in liver. (HE x40)

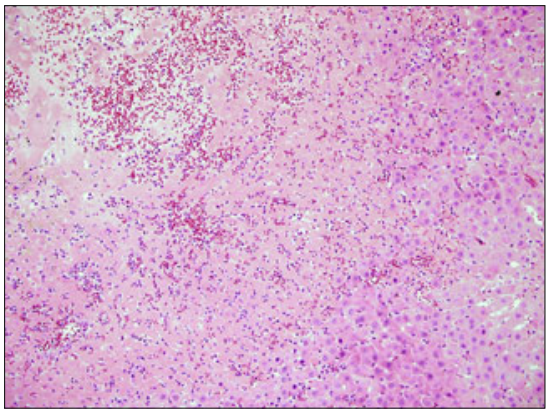

coloration time was $22.11 \pm 1.02 \mathrm{sec}$ in controls and $19.92 \pm 0.99$ sec in cases $(p>0.05)$.

\section{Histopathology of liver specimens}

Hypoperfusion and devascularization-induced necrosis was confirmed by histopathological evaluation in biopsy specimens (Figs 1, 2, 3).

\section{Kidney and liver function tests}

Renal function tests did not differ between control and liver injury groups at hours 0 to 24 (Tab. 2).

ALT and AST values significantly increased in each group at hour 24 compared to hour 0 . In addition, ALT values at hour 24 were lower in Group 2 than in Group 1. Direct bilirubin values were significantly higher in each group at hour 24. In Group 2, direct bilirubin values decreased significantly at hour 0 in comparison with Group 1 (Tab. 2).

\section{Oxidative stress and lipid peroxidation parameters}

Total antioxidant status decreased significantly at hour 24 after MB injection in Group $2(p=0.002)$. Additionally, antioxidant status was also significantly reduced in Group 2 when compared to Group 1 at hour $24^{\mathrm{t}}(\mathrm{p}=0.009)$ (Tab. 3).

Total oxidant status was significantly higher in Group 2 (liver injury) when compared to Group 1 (control) at hour 0 ( $\mathrm{p}<0.001)$. In Group 2, total oxidant status decreased at hour 24 compared to hour 0 (Tab. 3).

The levels of PON, SPON and arylesterase did not differ between Groups 1 and 2 at hours 0 and 24 (Tab. 3).

\section{Discussion}

In the present study, we evaluated the use of MB for identification of non-perfused tissue in experimentally induced devascularization injury in rat liver. As a result, MB did not stain the non-perfused area. The antioxidant properties of MB were also tested for oxidative stress and lipid peroxidation parameters in this experimental animal model. MB did not exhibit any beneficial effect on antioxidant status. However, MB showed to have a useful effect on oxidant status. Lipid peroxidation parameters did not alter due to devascularization or due to MB treatment. ALT and AST values have been found higher in each group at hour 24. These results may be attributed to traumatic injury due to surgical intervention. MB led to a decrease in ALT value in Group 2 at hour 24 compared to Group 1. Moreover, direct bilirubin at hour 0 was lower in Group 2 than in Group 1. These results may be interpreted as a suggestion that MB may have protective properties for the liver.

Tab. 2. Kidney and liver function tests between groups.

\begin{tabular}{|c|c|c|c|}
\hline Parameters & $\begin{array}{c}\text { Group } 1 \\
(\text { Control, } n=10)\end{array}$ & $\begin{array}{c}\text { Group } 2 \\
\text { (Liver injury, } \mathrm{n}=10 \text { ) }\end{array}$ & $\mathrm{p}^{\mathrm{a}}$ \\
\hline \multicolumn{4}{|l|}{ Hematocrit (\%) } \\
\hline Preoperative & $40.68 \pm 1.33$ & $42.96 \pm 1.69$ & 0.003 \\
\hline Postoperative hour 24 & $38.78 \pm 1.13$ & $42.57 \pm 1.92$ & $<0.001$ \\
\hline $\mathrm{p}^{\mathrm{b}}$ & 0.005 & 0.441 & \\
\hline \multicolumn{4}{|l|}{ Albumin } \\
\hline Preoperative & $1.82 \pm 0.49$ & $2.21 \pm 0.28$ & 0.039 \\
\hline Postoperative hour 24 & $2.58 \pm 0.75$ & $2.18 \pm 1.11$ & 0.364 \\
\hline $\mathrm{p}^{\mathrm{b}}$ & 0.047 & 0.941 & \\
\hline \multicolumn{4}{|l|}{ Urea $(\mathrm{mmol} / \mathrm{L})$} \\
\hline Preoperative & $46.5 \pm 6.76$ & $49.9 \pm 4.68$ & 0.207 \\
\hline Postoperative hour 24 & $69.4 \pm 14.63$ & $92 \pm 49.81$ & 0.185 \\
\hline $\mathrm{p}^{\mathrm{b}}$ & 0.001 & 0.024 & \\
\hline \multicolumn{4}{|l|}{ ALT (IU/L) } \\
\hline Preoperative & $65.9 \pm 16.22$ & $68.6 \pm 11.82$ & 0.675 \\
\hline Postoperative hour 24 & $668.8 \pm 411.19$ & $290.9 \pm 138.48$ & 0.013 \\
\hline $\mathrm{p}^{\mathrm{b}}$ & $<0.001$ & $<0.001$ & \\
\hline \multicolumn{4}{|l|}{$\overline{\mathrm{AST}}(\mathrm{IU} / \mathrm{L})$} \\
\hline Preoperative & $170.9 \pm 27.69$ & $181 \pm 41.92$ & 0.533 \\
\hline Postoperative hour 24 & $1261.2 \pm 456.35$ & $941.1 \pm 297.2$ & 0.079 \\
\hline$\underline{\mathrm{p}}^{\mathrm{b}}$ & $<0.001$ & $<0.001$ & \\
\hline \multicolumn{4}{|l|}{ Creatinine $(\mu \mathrm{mol} / \mathrm{L})$} \\
\hline Preoperative & $0.42 \pm 0.08$ & $0.43 \pm 0.09$ & 0.785 \\
\hline Postoperative hour 24 & $0.46 \pm 0.06$ & $0.48 \pm 0.14$ & 0.676 \\
\hline$\underline{\mathrm{p}}^{\mathrm{b}}$ & 0.223 & 0.213 & \\
\hline \multicolumn{4}{|l|}{ Total bilirubin $(\mu \mathrm{mol} / \mathrm{L})$} \\
\hline Preoperative & $0.1 \pm 0$ & $0.1 \pm 0$ & 1.000 \\
\hline Postoperative hour 24 & $0.11 \pm 0.04$ & $0.11 \pm 0.04$ & 1.000 \\
\hline $\mathrm{p}^{\mathrm{b}}$ & 0.343 & 0.343 & \\
\hline \multicolumn{4}{|l|}{ Direct bilirubin $(\mu \mathrm{mol} / \mathrm{L})$} \\
\hline Preoperative & $0.04 \pm 0.01$ & $0.03 \pm 0.01$ & 0.035 \\
\hline Postoperative hour 24 & $0.07 \pm 0.02$ & $0.07 \pm 0.02$ & 0.931 \\
\hline $\mathrm{p}^{\mathrm{b}}$ & $<0.001$ & $<0.001$ & \\
\hline
\end{tabular}

Data are given as mean \pm standard deviation.

$a^{p}$ values for between groups comparisons; $b^{p}$ values for in-group comparisons of pre- vs. postoperative values. 
Tab. 3. Oxidative stress and lipid peroxidation parameters.

\begin{tabular}{|c|c|c|c|}
\hline Parameters & $\begin{array}{c}\text { Group } 1 \\
(\text { Control, } \mathrm{n}=10)\end{array}$ & $\begin{array}{c}\text { Group } 2 \\
\text { (Liver injury, } \mathrm{n}=10 \text { ) }\end{array}$ & $\mathrm{p}^{\mathrm{a}}$ \\
\hline \multicolumn{4}{|l|}{$\begin{array}{l}\text { Total antioxidant status } \\
\text { (mmol Trolox equiv./L) }\end{array}$} \\
\hline Preoperative & $0.45 \pm 0.19$ & $0.53 \pm 0.09$ & 0.226 \\
\hline Postoperative hour 24 & $0.5 \pm 0.21$ & $0.25 \pm 0.18$ & 0.009 \\
\hline $\mathrm{p}^{\mathrm{b}}$ & 0.670 & 0.002 & \\
\hline \multicolumn{4}{|l|}{$\begin{array}{l}\text { Total oxidant status } \\
\left(\mu \mathrm{mol} \mathrm{H}_{2} \mathrm{O}_{2} \text { Equiv./L) }\right.\end{array}$} \\
\hline Preoperative & $7.15 \pm 3.22$ & $13.81 \pm 3.21$ & $<0.001$ \\
\hline Postoperative hour 24 & $4.29 \pm 1.58$ & $2.82 \pm 2.39$ & 0.12 \\
\hline $\mathrm{p}^{\mathrm{b}}$ & 0.066 & $<0.001$ & \\
\hline \multicolumn{4}{|l|}{ Paraoxonase (U/L) } \\
\hline Preoperative & $127.47 \pm 149.58$ & $103.43 \pm 108.88$ & 0.686 \\
\hline Postoperative hour 24 & $60.54 \pm 63.37$ & $43.9 \pm 62.84$ & 0.563 \\
\hline $\mathrm{p}^{\mathrm{b}}$ & 0.071 & 0.068 & \\
\hline \multicolumn{4}{|c|}{ Stimulated paraxonase (U/L) } \\
\hline Preoperative & $22.99 \pm 22.22$ & $22.84 \pm 17.31$ & 0.987 \\
\hline Postoperative hour 24 & $16.56 \pm 14.77$ & $11.4 \pm 15.43$ & 0.455 \\
\hline $\mathrm{p}^{\mathrm{b}}$ & 0.151 & 0.0037 & \\
\hline \multicolumn{4}{|l|}{ Arylesterase (U/L ) } \\
\hline Preoperative & $57.46 \pm 56.62$ & $56.38 \pm 46.64$ & 0.963 \\
\hline Postoperative hour 24 & $27.92 \pm 23.19$ & $25.39 \pm 22.73$ & 0.808 \\
\hline $\mathrm{p}^{\mathrm{b}}$ & 0.043 & 0.038 & \\
\hline
\end{tabular}

Data are given as mean \pm standard deviation.

${ }^{a} p$ values for between groups comparisons; ${ }^{b} p$ values for in-group comparisons of pre- vs. postoperative values.

Liver injury may lead to death as a result of uncontrolled bleeding or sepsis $(5,20)$. Non-operative management of stable liver trauma patients is associated with reduced mortality $(21,22)$. However, it is important to recognize traumatic liver devascularization since an initially stable patient may decompensate due to septic complications. Life-threatening liver necrosis resulting from devascularization may be diagnosed either intraoperatively or at autopsy $(23,24)$. It is not possible to detect the extent of liver necrosis exactly during surgery. Therefore, surgeons overestimate the borders and extend the resection area. The patients with extensive liver necrosis should be brought for definitive surgical resection (25). In a previous study, the importance of resecting areas of devascularized liver has been stressed (24).

It has been shown that it is possible to differentiate the ischemic area from the viable liver tissue by using MB in the evaluation of traumatic necrosis in a rabbit liver injury model (16). Since no perfusion occurred in devascularized area, only viable tissue retained the MB. Additionally, no adverse effect was observed due to MB usage. In accordance with this study, we confirmed that non-perfused areas of the liver remain unstained whereas the color of viable liver tissue changed from purple to dark blue in rat livers with experimentally induced devascularization injury. It was also safe as shown before. This study was performed in rats for the first time. Since CT scanning does not provide exact information about the difference between intrahepatic hemorrhage and devascularization injury in the liver, it seems feasible to inject MB into the portal vein for anatomically precise resection of nonperfused liver tissue due to devascularization in patients. Further studies are required to confirm the effectiveness and safety of MB to be able to use it in humans.
A few studies show that oxidative stress and lipid peroxidation increases due to liver necrosis resulting from devascularization (14, 15). Exact mechanisms have not been clearly demonstrated. In this study, we also tested the antioxidant activity. Our hypothesis was that both oxidative stress and lipid peroxidation play a role in the pathophysiology of devascularization injury in the liver and the use of MB may be useful against these factors. To test this hypothesis, total oxidant and antioxidant status, PON and arylesterase were measured in blood samples. There were two experimental animal groups each including 10 rats, (control and liver injury group). Blood samples were collected after injection of MB into animals (before and thereafter at hour 24 of experiment).

In the present study, total antioxidant status decreased significantly in Group 2 at hour 24 in comparison with that at hour 0 as well as with Group 1 at hour $24^{\mathrm{t}}$. Our results show that antioxidant activity impaired at hour 24 due to liver injury and injection of MB does not produce any beneficial effect on antioxidant status.

In respect of oxidant status, it was found to be increased significantly in Group 2 (liver injury) at hour 0 when compared to Group1 (control). In addition, in Group 2, total oxidant status was lower at hour 24 than that at hour 0. It is likely that MB has a useful effect on oxidant status.

Our results suggest that oxidative stress may play a role in the pathophysiology of liver necrosis due to devascularization injury. MB exhibited beneficial effect on oxidant status.

PON, SPON and aryl esterase activities were also determined in two experimental animal groups. No significant change was found between groups. Our results suggest that lipid peroxidation has no role in the pathophysiology of devascularization injury in the liver.

Due to technical reasons it was not possible to evaluate the oxidative/antioxidative stress and lipid peroxidation parameters in liver tissue. Therefore, it is not possible to comment on the contribution of tissue activity of these parameters to pathophysiology. On the other hand, this is an animal study which makes it difficult to apply the results to human beings. These factors are limitations for the present study. However, the application of $\mathrm{MB}$ during surgery promises a new method for identification of nonperfused areas due to liver devascularization.

In conclusion, MB seems useful for identification of nonperfused tissue in devascularization-induced liver injury. Since MB showed a beneficial effect on oxidant status in this study, it may be feasible to use MB as an antioxidant agent in liver injury due to devascularization. Further studies are required to confirm these results.

\section{References}

1. Cogbill TH, More EE, Jurkovich GJ, Feliciano DV, Morris JA, Mucha P. Severe hepatic trauma: a multicenter experience with 1,335 liver injuries. J Trauma 1988; 28 (10): 1433-1438.

2. Anderson IB, Al Saghier M, Kneteman NM, Bigam DL. Liver trauma: Management of devascularization injurries. J Trauma 2004; 57 (5): 1099-1104. 
3. Jiang H, Wang J. Emergency strategies and trends in the management of liver trauma. Front Med 2012; 6 (3): 225-233.

4. Feliciano DV, Pachter HL. Hepatic trauma revisited. Curr Probl Surg 1989; 26 (7): 453-524.

5. Parks RW, Chrysos E, Diamond T. Management of liver trauma. Br J Surg 1999; 86 (9): 1121-1135.

6. Beal SL. Fatal hepatic hemorrhage: an unresolved problem in the management of complex liver injuries. J Trauma 1990; 30 (2): 163-169.

7. Hollands MJ, Little JM. The role of hepatic resection in the management of blunt liver trauma. World J Surg 1990; 14 (4): 478-482.

8. Moore EE, Cogbill TH, Jurkovich GJ, Shackford SR, Malangoni MA, Champion HR. Organ injury scaling: spleen and liver. J Trauma 1995; 38 (3): 323-324.

9. Swift C, Garner JP. Non-operative management of liver trauma. J R Army Med Corps 2012; 158 (2): 85-95.

10. Nasrinossadat A, Ladan F, Fereshte $\mathbf{E}$ et al. Marking non-palpable breast masses with injected methylene blue dye, an easy, safe and low cost method for developing countries and resource-limited areas. Asian Pac J Cancer Prev 2011; 12 (5): 1189-1192.

11. Jepsen RK, Ingeholm P, Lund EL. Upstaging of early colorectal cancers following improved lymph node yield after methylene blue injection. Histopathol 2012; 6 1(5): 788-794.

12. Salaris SC, Babbs CF, Voorhees WD 3rd. Methylene blue as an inhibitor of superoxide generation by xanthine oxidase. A potential new drug fort he attenuation ischemia/reperfusion injury. Biochem Pharmacol 1991; 42 (3): 499-506.

13. Galili Y, Bem-Abrahan R, Weinbroum A et al. Methylene blue prevents pulmonary injury after intestinal ischemia-reperfusion. J Trauma 1998; 45 (2): 222-226.

14. Kusmic C, Boggi $\mathbf{U}$, Bellini $\mathbf{R}$ et al. Oxidative stress in fulminant hepatic failure: comparison of two pig models with and without liver necrosis. Hepatogastroenterol 2001; 48 (39): 762-769.
15. Vlahakos D, Arkadopoulos N, Kostopanagiotou G et al. Deferoxamine attenuates lipid peroxidation, blocks interleukin-6 production, ameliorates sepsis inflammatory response syndrome, and confers renoprotection after acute hepatic ischemia in pigs. Artif Organs 2012; 36 (4): 400-408.

16. Behdad A, Hosseinpour M. Methylene blue usage in the evaluation of traumatic necrosis in a rabbit liver injury. Turk J Trauma Emerg Surg 2009; 15 (4): 337-341.

17. Erel O. A novel automated method to measure total antioxidant response against potent free radical reactions. Clin Biochem 2004; 37 (2): 112-119.

18. Erel O. A new colorimetric method for measuring total oxidant status. Clin Biochem 2005; 38 (12): 1103-1111.

19. Toy H, Camuzcuoğlu H, Celik H, Erel O, Aksoy N. Assesment of serum paraoxonase and arylesterase activities in early pregnancy failure. Swiss Med Wkly 2009; 139 (5-6): 76-81.

20. Kasai T, Kobayashi K. Searching fort the best operative modality for severe hepatic injuries. Surg Gynecol Obstet 1993; 177 (6): 551-555.

21. Pachter HL, Spencer FC, Hofstetter SR, Liang HG, Coppa GF. Significant trends in the treatment of hepatic trauma:experience with 411 injuries. Ann Surg 1992; 215 (5): 492-502.

22. Malhotra AK, Fabian TC, Croce MA et al. Blunt hepatic injury: a paradigm shift from operative on non-operative management in 1990s, Ann Surg 2000; 231 (6): 804-813.

23. Hirshberg A, Walden R. Damage control for abdominal trauma. Surg Clin Morth Am 1977; 77 (4): 813-820.

24. Strong RW, Lynch SV, Wall DR, Liu CL. Anatomic resection for severe liver trauma. Surgery 1998; 123 (3): 251-257.

25. Smadja C, Traynor O, Blumgart LH. Delayed hepatic resection for major liver injury. Br J Surg 1982; 69 (7): 361-364.

Received August 24, 2013. Accepted May 16, 2014. 